\title{
MOLINOS DE VIENTO EN ANDALUCÍA: NUEVAS HERRAMIENTAS PARA SU PUESTA EN VALOR
}

\author{
José Ignacio Rojas Sola \\ Mercedes Cristina Gómez Bueno \\ Miguel Castro García \\ Departamento de Ingeniería Gráfica, Diseño y Proyectos. Universidad de Jaén \\ jirojas@ujaen.es
}

\section{RESUMEN}

Los molinos de viento son un ejemplo de arquitectura vernácula y patrimonio preindustrial agrario, pudiendo ser empleados como elementos impulsores del desarrollo rural en los municipios donde se ubican. El presente artículo muestra nuevas herramientas para su puesta en valor. Para ello, se ha desarrollado una metodología de valorización del paisaje cuyos resultados forman parte de un Sistema de Información Geográfica (SIG), obteniendo un conjunto de rutas molinares como recurso económico sostenible.

Palabras clave: molino de viento, patrimonio cultural, rutas turísticas, SIG, desarrollo local.

\begin{abstract}
Windmills are an example of vernacular architecture and agricultural preindustrial heritage. It can be used as entities that promote rural development in the municipalities where they are located. This article shows new tools for their valorization. To do this, we have developed a landscape valuation methodology whose results will be part of a Geographic Information System (GIS). Thus, it is obtained a set of milling tourist routes that will be a sustainable economic resource.
\end{abstract}

Key words: windmills, cultural heritage, tourist routes, GIS, local development.

Fecha de recepción: diciembre 2011.

Fecha de aceptación: enero 2013. 


\section{INTRODUCCIÓN}

Los molinos de viento son uno de los ejemplos de arquitectura vernácula más emblemáticos, ya sean los referidos por Miguel de Cervantes en el Quijote o de cualquier otra tipología existente en España. De hecho, la tipología de molino de viento en la Mancha presenta unas características diferenciadoras de las del resto de España, como es la forma rectangular de sus aspas frente a las velas latinas triangulares mediterráneas, pero también como consecuencia de las partes funcionales de estos ingenios eólicos que afectaban a la arquitectura industrial (Rojas Sola et al., 2006).

Sin embargo, la puesta en valor de estos 'gigantes' es deficiente, puesto que en muchos casos, se reduce a la visita presencial gestionada por la Oficina de Turismo de la localidad o por una empresa privada que gestiona los mismos. Por ejemplo, en Campo de Criptana (Ciudad Real), existen todavía 10 molinos de los 33 que llegaron a convivir en la Sierra de los Molinos (3 de ellos Bien de Interés Cultural (BIC)), siendo la Oficina de Turismo la que gestiona la visita a los mismos, y presentando una escasa difusión a través de Internet. Asimismo, tampoco se han desarrollado herramientas que potencien el desarrollo local de las localidades donde se enclavan estos molinos, lo que sin duda, sería de gran ayuda para promover el empleo.

\subsection{El patrimonio histórico molinar eólico de Andalucía}

Para cubrir estas deficiencias, y particularizando para Andalucía, se ha completado un Proyecto de Investigación de Excelencia titulado 'El patrimonio histórico molinar eólico de Andalucía', dirigido por el Catedrático Prof. Dr. José Ignacio Rojas Sola, responsable del Grupo de Investigación 'Ingeniería Gráfica y Arqueología Industrial' del II Plan Andaluz de Investigación, Desarrollo e Innovación de la Junta de Andalucía, donde se recoge un detallado inventario de los molinos de viento harineros que aún perviven en la comunidad autónoma con un total de 89 ejemplares, congregándose en su mayoría en las provincias de Almería, Huelva y Cádiz, ordenadas según el número de ejemplares.

Se ha llevado a cabo una amplia catalogación de los mismos en la que se tratan aspectos tipológicos, de protección y conservación, puesta en valor, accesibilidad o posicionamiento GPS (del inglés, Global Positioning System), entre otros, y recopilándose fotografías, textos y bibliografía referentes a los mismos.

En la fase de inventariado también se ha considerado la búsqueda semántica de las localizaciones de estos ingenios eólicos, proceso conocido como Recuperación de Información Geográfica (RIG) o GIR (del inglés, Geographic Information Retrieval). Concretamente los recursos históricos que se han manejado como fuentes de localización geográficas de molinos de viento son:

- Base de datos de BIC, que es la figura jurídica de protección del Patrimonio Histórico Español regulada por la Ley 16/1985 de 25 de junio, estando los molinos de viento dentro de la clasificación de 'monumento'.

- Sistema de Información del Patrimonio Histórico de Andalucía (SIPHA).

- Catastro del Marqués de la Ensenada, documento cuya elaboración fue ordenada por el rey Felipe VI a propuesta de su Ministro el Marqués de la Ensenada contestándose 
en cada localidad 40 preguntas, y siendo su pregunta 15 la relativa a 'minas, salinas, molinos y otros artefactos', extrayéndose a partir de esta cuestión información relativa a la localización geográfica, funcionamiento y otras características de los molinos de viento andaluces.

- Diccionario geográfico-estadístico-histórico de España y sus posesiones de Ultramar, obra publicada por Pascual Madoz entre los años 1846 al 1850, que se compone de 16 volúmenes donde se analizan todas las poblaciones de España. La importancia de esta obra radica en que describe bienes que hoy en día se consideran patrimoniales. En este caso, el valor que aporta al presente trabajo de investigación es la localización geográfica de los molinos de viento.

Asimismo, uno de los objetivos principales ha sido el desarrollo de un Sistema de Información Geográfica (SIG) que contemplara las rutas molinares que se han proyectado en función de diversas variables, como herramienta vertebradora de desarrollo local siendo la valoración paisajística de las mismas el parámetro crítico para su propuesta. En consecuencia, se descubre el lugar donde se enclavan los citados molinos que hoy día perviven en desuso, siendo referentes paisajísticos y evidencia palpable de la evolución y desarrollo de las localidades donde se erigen. Esta última parte, es la investigación que se presenta en este artículo, donde se desglosa la metodología desarrollada y cómo se han creado dichas rutas molinares como un elemento más en el desarrollo rural de las localidades afectadas.

\subsection{Ingenios eólicos: tipologías}

Los molinos de viento son edificaciones rústicas cuyo diseño se ha mejorado desde algunos siglos a.C., apareciendo la primera referencia de estos ingenios en Extremo Oriente. Son construcciones funcionales que se instalaron en los campos como motores de subsistencia, enclavados en lugares estratégicos donde se obtienen los mejores rendimientos en la molienda del grano.

El historiador y antropólogo Julio Caro Baroja hace una amplia disertación sobre molinos de viento y denomina a estos ingenios eólicos andaluces como 'molinos mediterráneos' o molinos de torre con techo giratorio (Caro Baroja, 1996). Apoyándose en los estudios del alemán Fritz Krüger (Krüger, 1950) y al igual que éste, Caro Baroja agrupa a estos ingenios en tres tipologías distintas atendiendo a la forma de sus aspas: con eje atravesado por cuatro pares de varas, que sostienen cuatro velas triangulares; con eje que sostiene cuatro aspas, compuestas cada una de una vara central, dos vergas laterales, paralelas a aquélla y ocho travesaños de velas rectangulares, y con eje que sostiene también cuatro aspas, compuestas cada una de una vara central, cuatro o seis vergas laterales y paralelas con quince o más travesaños, y con velas rectangulares largas y estrechas.

Los ejemplares recogidos en este estudio son molinos de viento mediterráneos de tipología A según Krüger, o lo que es lo mismo, molinos de velas triangulares con paralelismos con los de Portugal, Madeira, Azores, Cartagena o Grecia, entre otros.

Son construcciones de torre cilíndrica y vela latina con techo cónico que se sitúa sobre plataforma anular móvil girando gracias a una rueda inserta en un carril de madera. El conjunto alcanza unos 7 u 8 metros de altura según provincia, siendo sus gruesos muros de mampostería de piedra a veces enfoscada y enlucida por mortero de cal. Posee dos plantas 
bien diferenciadas, una primera o baja que servía de recogida y almacén de la harina, y una segunda planta donde se hallan el eje, los engranajes y demás elementos o mecanismos de la molienda.

Estos molinos son edificaciones determinadas por unas condiciones climáticas específicas y por el uso de materiales autóctonos (Agudo Torrico, 1999), adaptadas tanto al medio físico en el que se ubican como a la actividad desarrollada por sus habitantes (Romero Torres, 2000). Sin embargo, no todos los ejemplares recogidos en este estudio son similares, pues aunque entre ellos comparten la tipología A de Krüger de molinos de viento 'mediterráneos', en cada provincia se observan disparidades en elementos no sólo arquitectónicos sino también funcionales.

Ejemplo de ello, se observa en la localidad gaditana de Vejer de la Frontera donde estos ingenios son muy robustos, poseen dos puertas de acceso así como tres ventanas con funciones de orientación del velamen y de iluminación en su planta superior (Fig.1), mientras los existentes en la comarca onubense del Andévalo Occidental tan sólo poseen una puerta de acceso, rematando su torre con una hilera de ladrillos vistos y franja de lajas de piedra a modo de decoración (Fig. 2).

Por otro lado, un aspecto diferenciador importante se encuentra en los molinos de viento que perduran en los distintos municipios almerienses que incluyen en su mecanismo un regulador centrífugo o sistema de alivio automático (separación de las piedras de moler), elemento innovador en este tipo de construcción e inexistente en los demás ejemplares andaluces que poseen un sistema de alivio manual, lo que permite alcanzar una completa regulación de la molienda y, en consecuencia de la calidad del producto final (harina) (Rojas Sola y Amezcua Ogáyar, 2005). A continuación se presenta un cuadro sinóptico (Cuadro 1) que presenta la información básica de los molinos citados.

MOLINO DE VIENTO DE SAN FRANCISCO (VEJER DE LA FRONTERA, CÁDIZ)

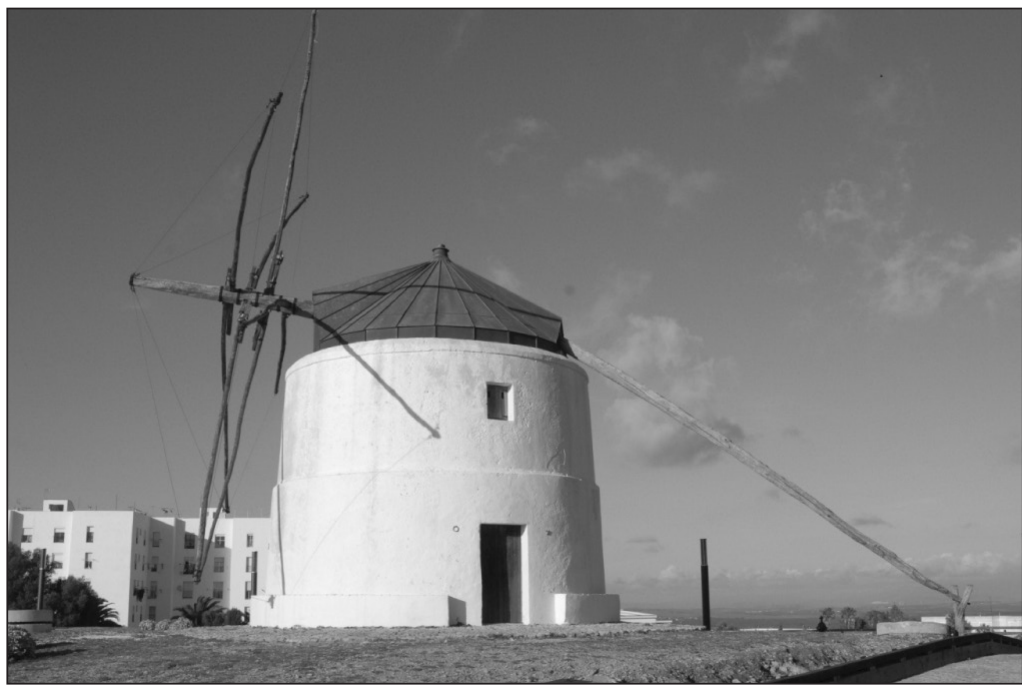

Fuente: Elaboración propia. 
Figura 2

MOLINO DE VIENTO DE LA SOLANA (EL GRANADO, HUELVA)

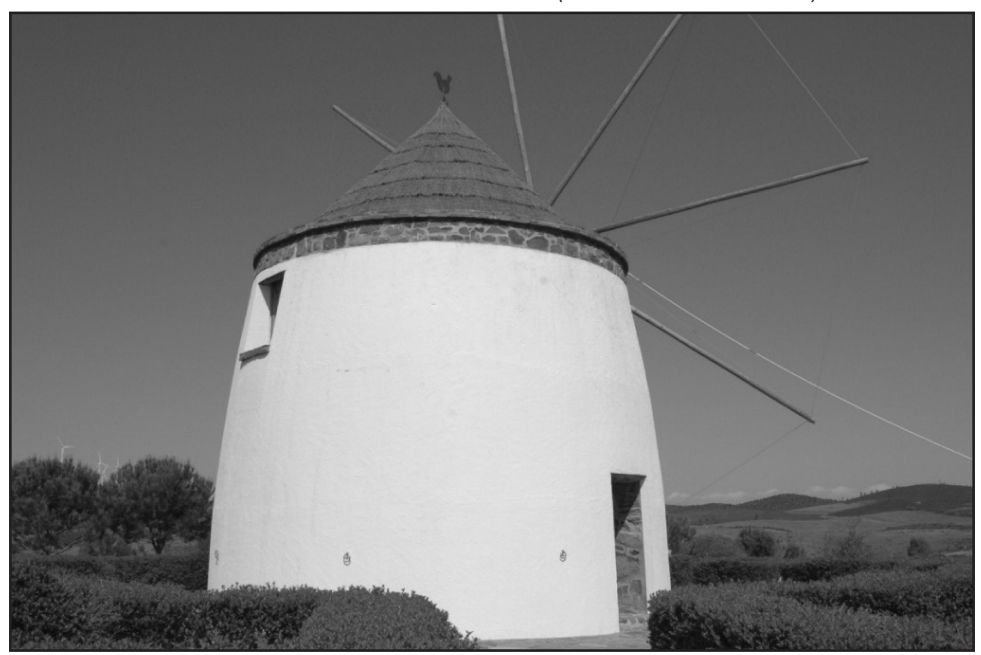

Fuente: Elaboración propia.

Cuadro 1

CARACTERÍSTICAS DIFERENCIADORAS ENTRE TIPOLOGÍAS DE MOLINOS DE VIENTO

\begin{tabular}{|c|c|c|c|}
\hline & & \multicolumn{2}{|c|}{ Molino de viento } \\
\hline & & De torre & Mediterráneo \\
\hline \multirow{4}{*}{ Velamen } & Tipología & Aspas & Velas \\
\hline & Número & 4 & 8 \\
\hline & Diámetro del rotor (m) & 18 & 12 \\
\hline & Superficie por aspa/vela $\left(\mathrm{m}^{2}\right)$ & 13,87 & 9,54 \\
\hline \multicolumn{2}{|c|}{$\mathrm{N}^{\circ}$ de plantas del edificio } & 3 & 2 \\
\hline \multicolumn{2}{|c|}{ Regulador de la molienda automático } & No & Sí \\
\hline
\end{tabular}

Fuente: Elaboración propia.

\subsection{Patrimonio preindustrial agrario}

Los molinos de viento harineros son construcciones locales que se hicieron para el desarrollo de oficios, fruto de la etapa preindustrial (Tillería González, 2010), antes de la irrupción del vapor, la electricidad y otras fuentes de energía en las técnicas fabriles. Eran centros productivos de gran importancia en el contexto de la economía de subsistencia reinante en el mundo rural que con el tiempo fueron cayendo en el olvido con el progresivo abandono de los campos, acusados procesos migratorios, transformaciones del medio rural, pérdida de oficios, decadencia de las actividades agrarias tradicionales (Bustos Gisbert, 2006) y creaciones 
de grandes industrias de panificación que serían más rentables para la producción (Alegre Carvajal, 2003). Aun así, algunos como el molino de Manuel Gil en la localidad de Fernán Pérez (Almería), siguieron moliendo hasta la década de los 70 del siglo XX, sobreviviendo a los cambios tecnológicos acontecidos y a la fragilidad económica, social y funcional que acaecía en esos momentos (Bustos Gisbert, 2006).

Por tanto, los molinos de viento que poblaron y aún pueblan algunos campos andaluces forman parte del patrimonio preindustrial agrario (arquitectura de producción), siendo construcciones desarrolladas amplia y diversamente en ricas zonas de cereales, monocultivo por excelencia en la producción tradicional andaluza donde además, se registran valores significativos de viento que permiten transformar la energía cinética en energía mecánica, a través de la cual, se acciona la maquinaria para la molienda del grano.

La provincia de Almería, junto a las de Huelva y Cádiz, ordenadas según el número de molinos hallados, son de los enclaves españoles que registran más días de viento al año. Por ejemplo, Cádiz es azotada durante muchos días al año por fuertes rachas de viento de Levante, y Almería debido a su singular ubicación geoespacial, también es considerada provincia con alto índice de vientos a lo largo del año, por lo que en su momento fueron lugares propicios para la construcción y ubicación de estos ingenios, aprovechando así la fuerza de los vientos en la molienda de cereal y la obtención de la harina (Viedma Muñoz, 1998).

Estos ingenios forman parte de la arquitectura etnológica o vernácula la cual ha estado siempre a la sombra del resto de manifestaciones arquitectónicas a pesar de su relevancia social y cultural, amenazada por carecer de grandiosidad y monumentalidad y caer en desuso y deterioro (Carrera Díaz, 2004), convirtiéndose en construcciones obsoletas que no han sido intervenidas ni recuperadas debido a la falta de sensibilidad hacia este patrimonio, careciendo de valoración social y cultural expresada a través de una profunda indiferencia hacia el patrimonio ‘más modesto’ durante décadas (Hernández León, 1997), pero que hoy día tras la legislación de Patrimonio Histórico existente -son bienes integrantes del Patrimonio Etnográfico Andaluz los parajes, espacios, construcciones o instalaciones vinculadas a formas de vida, cultura, actividades y modos de producción propias de la comunidad de Andalucía(Ley 14/2007 de Patrimonio Histórico de Andalucía), se han convertido en hitos paisajísticos que acercan al ciudadano a la cultura de la agricultura, concebida como patrimonio ya que las prácticas agrarias tras caer en decadencia, han cobrado un indudable valor a lo largo de la historia (Silva Pérez, 2009).

Organizaciones internacionales como ICOMOS o UNESCO entre otras, han comenzado a definir y caracterizar este patrimonio estableciendo criterios e instrumentos para su protección y gestión puesto que se trata de un patrimonio multidimensional que aúna no sólo aquellos bienes muebles e inmuebles propios de los oficios, sino también bienes inmateriales, culturales y naturales (Martínez Yánez, 2010). El objetivo primordial de ello, es recuperar el patrimonio sin privarle de su contexto histórico-territorial; de ahí, la revalorización ya no sólo de estos ingenios, sino de la arquitectura popular en general, sus tradiciones y costumbres que se hallaban en fase de abandono y olvido, siendo una manera fácil de rescatar la memoria histórica de cada comarca (Guerra de Hoyos, 1997).

Actualmente, este patrimonio vernáculo, preindustrial, agrario, presenta un alto valor cultural como manifestación del desarrollo económico y social y expresión de identidad de 
muchos territorios (Pardo Abad, 2010), adquiriendo además un significado especial como recurso susceptible de generar riqueza (Caravaca Barroso et al., 1997), convirtiéndose en potencial para el turismo de interior, y revalorizándose así el medio rural que acoge a estas construcciones (Pardo Abad, 2010). Así pues, dado que un verdadero protagonista del hecho patrimonial es el territorio, se precisa de la escala territorial para se entendido, protegido y gestionado.

\section{METODOLOGÍA}

\subsection{Paisajes molinares}

Los molinos de viento que aún perviven forman parte hoy día de un paisaje cultural, no degradado, aunque sí antropizado (Rodrigo Cámara et al., 2012) y, desde donde se divisan amplias panorámicas convirtiéndose en auténticos miradores que ofrecen al visitante magníficas vistas del entorno circundante. Todos ellos vienen a conformar espacios de gran valor paisajístico entremezclados con un rico legado cultural, y que tanto la construcción en sí como el propio entorno donde se erigen, son dignos de protección y valoración social (Sobrino Simal, 1997).

Según el Convenio Europeo del Paisaje (AA.VV., 2000), se entiende por paisaje «cualquier parte del territorio tal y como lo percibe la población, cuyo carácter sea el resultado de la acción e interacción de factores naturales y/o humanos».

En la Convención del Patrimonio Mundial (AA.VV., 2008), en su artículo 1 se dice que «Los paisajes culturales representan la obra combinada de la naturaleza y el hombre» y en su artículo 47 se considera que los paisajes culturales «ilustran la evolución de la sociedad y los asentamientos humanos en el transcurso del tiempo, bajo la influencia de las restricciones físicas y lo las oportunidades presentadas por su ambiente natural de las sucesivas fuerzas sociales, económicas y culturales, tanto internas como externas».

Para el profesor Mata Olmo (Mata Olmo, 2008), el paisaje es «resultado de la relación sensible de la gente con su entorno percibido, cotidiano o visitado».

Los lugares donde se alzan los ejemplares estudiados en este artículo, forman parte de un rico paisaje cultural agrario en el que conviven entornos de calidad y huellas culturales fruto de procesos históricos y actividades socioeconómicas que de alguna manera moldearon ese paisaje vivo que hoy día se nos ofrece (Fernández Cacho et al., 2008). Estos son paisajes continuos «que retienen un papel social activo en la sociedad contemporánea, estrechamente asociado con la forma tradicional de vida y cuyo proceso evolutivo está todavía en curso. Al mismo tiempo, exhibe evidencias materiales significativas de esta evolución en el transcurso del tiempo» (Martínez Yánez, 2010), reuniendo aspectos diversos tales como naturales, históricos, funcionales, psicológicos, adquiriendo un valor simbólico y subjetivo reflejo de la cultura e identidad de un pueblo (Hernández Hernández, 2009).

Andalucía se caracteriza por poseer una alta diversidad paisajística, y muestra de ello son las tres provincias andaluzas donde se recogen la mayor parte de estos molinos de viento. En la localidad gaditana de Vejer de la Frontera (Comarca de La Janda), se registran los valores más altos de diversidad paisajística junto a la Comarca de Níjar en Almería con un paisaje singular y tradicional (López Gómez y Cifuentes Vélez, 2001); por el contrario, la Comarca 
del Andévalo (Huelva), registra valores de alta naturalidad paisajística caracterizada por el predominio de cobertura vegetal natural (AA.VV., 2005b); por ello, presenta un elevado valor ya no sólo cultural, sino también paisajístico debido a la oferta natural de sus entornos, y de ahí, que las tres comarcas anteriormente mencionadas, formen parte del registro de Paisajes de Interés Cultural de Andalucía (PICA), paisajes reconocidos y emblemáticos con significado histórico.

\subsection{Valorización del paisaje}

La valorización del paisaje constituye el parámetro clave dentro de la investigación que presenta este artículo. Para ello se ha tomado como referencia la metodología propuesta por el Catedrático Profesor Dr. Ignacio Cañas Guerrero de la Universidad Politécnica de Madrid sobre valoración del paisaje. Gracias a la misma, se ha podido detallar de forma cuantitativa cuál es la calidad natural de los paisajes en los que se encuentran enclavados estos ingenios eólicos, llevando a la práctica su propuesta de cuantificación in situ (Cañas Guerrero, 1995).

Esta metodología consiste en segmentar el paisaje en tres atributos: físicos, artísticos y psicológicos. A su vez, cada atributo se desglosa en una serie de descriptores que están formados por las variables de trabajo, de forma que a las variables se les asigna un valor tabulado en el momento en el que se esté realizando el trabajo de campo in situ. Como resultado se obtiene que los atributos físicos están compuestos por 11 descriptores que albergan 33 variables, los atributos artísticos por 3 descriptores con 9 variables, y los atributos psicológicos por 2 descriptores con un total de 5 variables, tal y como vienen especificados en el Cuadro 2 .

Cuadro 2

FICHA DESCRIPTIVA DE LA CALIDAD PAISAJÍSTICA

\begin{tabular}{|c|c|c|c|c|c|}
\hline \multicolumn{6}{|c|}{ ATRIBUTOS FÍSICOS } \\
\hline \multicolumn{6}{|l|}{ AGUA } \\
\hline Tipo & Zona pantanosa & Arroyo & Rio & Lago/Pantano & Mar \\
\hline Orillas & Sin Vegetación & & Con vegetación & & Mucha vegetación \\
\hline Movimiento & Ninguno & Ligero & Meandros & Rápido & Cascada \\
\hline Cantidad & Baja & & Media & & Alta \\
\hline \multicolumn{6}{|c|}{ FORMA DEL TERRENO } \\
\hline Tipo & Llano & Costa & Colinas & Montañoso & \\
\hline \multicolumn{6}{|c|}{ VEGETACIÓN } \\
\hline Cubierta $(\%)$ & $<5$ & $5-25$ & $25-50$ & $50-75$ & $>75$ \\
\hline Diversidad & Poca & & Presente & & Bastante \\
\hline Calidad & Regular & & Buena & & Muy buena \\
\hline Tipo & Cultivo de secano & Cultivo de regadío & Arbustivo & Pradera & Arbóreo \\
\hline \multicolumn{6}{|l|}{ NIEVE } \\
\hline Cubierta $(\%)$ & $<5$ & $5-25$ & $25-50$ & $50-75$ & $>75$ \\
\hline \multicolumn{6}{|l|}{ FAUNA } \\
\hline Presencia & Presentes & & & & Abundantes \\
\hline Interés & Mediocre & & & & Bueno \\
\hline Fácil-verse & Mediocre & & & & Buena \\
\hline
\end{tabular}




\begin{tabular}{|c|c|c|c|c|c|}
\hline \multicolumn{6}{|l|}{ USOS DEL SUELO } \\
\hline Tipo & Industrial & Minero & Urbano & Agrícola & Salvaje \\
\hline Intensidad de poblado & Muy poblado & & Poblado & & Poco poblado \\
\hline \multicolumn{6}{|l|}{ VISTAS } \\
\hline Amplitud $\left({ }^{\circ}\right)$ & $<45$ & $45-90$ & $90-180$ & $180-270$ & $>270$ \\
\hline Tipo & Baja & & Media & & Panorámica \\
\hline \multicolumn{6}{|l|}{ SONIDOS } \\
\hline Presencia & Presentes & & & & Dominantes \\
\hline Tipo & Molestos & & Indiferentes & & Armoniosos \\
\hline \multicolumn{6}{|l|}{ OLORES } \\
\hline Presencia & \begin{tabular}{|l|} 
Presentes \\
\end{tabular} & & & & Dominantes \\
\hline Tipo & Molestos & & Indiferentes & & Armoniosos \\
\hline \multicolumn{6}{|c|}{ RECURSOS CULTURALES } \\
\hline Presencia & Presentes & & & & Abundantes \\
\hline Tipo & Popular & & & & Histórico \\
\hline Facilidad de verse & Mediocre & & & & Buena \\
\hline Interés & Mediocre & & & & Bueno \\
\hline \multicolumn{6}{|c|}{ ELEMENTOS QUE ALTERAN EL CARÁCTER } \\
\hline Intrusión & Bajo & & Medio & & Alto \\
\hline Fragmentación & Algo & & Medio & & Bastante \\
\hline Línea de horizonte & Algo & & & & Bastante \\
\hline Tapa vistas & Algo & & & & Bastante \\
\hline \multicolumn{6}{|c|}{ ATRIBUTOS ARTÍSTICOS } \\
\hline \multicolumn{6}{|l|}{ FORMA } \\
\hline Diversidad & Alguna & & & & Dominante \\
\hline Contraste & Algo & & & & Bastante \\
\hline Compatibilidad & No & & & & Sí \\
\hline \multicolumn{6}{|l|}{ COLOR } \\
\hline Diversidad & \begin{tabular}{|l|} 
Alguna \\
\end{tabular} & & & & Dominante \\
\hline Contraste & Alguna & & & & Dominante \\
\hline Compatibilidad & No & & & & Sí \\
\hline \multicolumn{6}{|l|}{ TEXTURA } \\
\hline Diversidad & Alguna & & & & Dominante \\
\hline Contraste & Alguno & & & & Dominante \\
\hline Compatibilidad & No & & & & Sí \\
\hline \multicolumn{6}{|c|}{ ATRIBUTOS PSICOLÓGICOS } \\
\hline \multicolumn{6}{|l|}{ UNIDAD } \\
\hline Línea de estructura & Alguna & & & & Dominante \\
\hline Proporción & Alguna & & & & Dominante \\
\hline \multicolumn{6}{|l|}{ EXPRESIÓN } \\
\hline Afectividad & Alguna & & & & Dominante \\
\hline Estimulante & Alguna & & & & Dominante \\
\hline Simbolismo & Alguna & & & & Dominante \\
\hline
\end{tabular}

Fuente: (Cañas Guerrero, 1995). 
Los atributos físicos son los elementos visibles, tangibles y sus propiedades, incluyendo descriptores como el agua, forma del terreno, vegetación, nieve, fauna, usos del suelo, vistas, sonidos, olores, recursos culturales y elementos que alteran el carácter, y todas ellas con sus respectivas variables.

Los atributos artísticos contemplan aquellas abstracciones de elementos físicos del paisaje que se combinan para formar pautas o modelos en el ojo humano siendo sus descriptores la forma, el color y la textura con sus distintas variables.

Por último, los atributos psicológicos, es decir, un grado más de abstracción pues son las propiedades del paisaje que no son visibles. En estos se contemplan los descriptores de unidad y expresión (Gobster y Chenoweth, 1989).

Una vez completado el trabajo de campo con la toma de datos en los distintos puntos de observación, se obtiene una puntuación del valor del paisaje final $\left(V_{m}\right)$ con valores comprendidos entre 0 a 100 que se relacionará con una calidad paisajística concreta que se encuentra tabulada en rangos de valores determinados. En concreto, la expresión de la $V_{m}$ es:

$$
V_{m}=\sum_{x=1}^{n} V_{x i}
$$

donde $V_{x i}$ corresponde al valor de cada descriptor del atributo en estudio. Al mismo tiempo, $V_{x i}$ depende del valor de las variables afectado a su vez por una serie de coeficientes como se observa en la siguiente expresión:

$$
V_{x i}=Z \cdot P_{j}+K \cdot f_{x i} \cdot \sum_{j=n}^{j=m} V_{x j}
$$

donde:

$Z$ y $K$ son coeficientes cuyo valor lógico es de 0 ó 1 , con la particularidad de que cuando un coeficiente tiene un valor, el otro tiene el opuesto.

$P_{j}$ es el peso de la variable de descriptor x, que sólo se define cuando $Z=0$ y $K=1$.

$f_{x i}^{j}$ es el factor de multiplicación para la variable i perteneciente al atributo x. Sólo toma valor cuando $Z=1$ y $K=0$.

$V_{x j}$ es el valor otorgado durante la observación in situ de la variable i del descriptor x.

Tanto los coeficientes $Z$ y $K$ como $P_{j}$ y $f_{x i}$ dependen de cada variable en estudio y su valor está estipulado de forma general para cualquier paisaje considerado.

En consecuencia, gracias a estas expresiones se obtiene el valor cuantitativo de $V_{m}$ que se relaciona con un valor cuantitativo tabulado del paisaje en función de la puntuación obtenida: 'Degradado' para valores de 0 a 20, 'Deficiente' para valores entre 20 y 32, 'Mediocre' entre 32 y 44, 'Buena' con valores entre 44 y 56, 'Notable' entre 56 y 68, 'Muy Buena' con valores entre 68 y 80, y 'Excelente' para valores comprendidos entre 80 y 100.

Es de destacar que el método es sensible a pequeños cambios en el paisaje que son reflejados en la puntuación final. Sin embargo, para algunas variables es necesario recurrir a la información recogida in situ y completarla con la información de la cartografía disponible, 
y con otro tipo de información recogida en la bibliografía, como la climática, de relaciones económicas, históricas o sociales, entre otras.

Tras llevar a la práctica la metodología in situ anteriormente expuesta, se obtuvieron resultados de gran calidad paisajística, mostrándose así una vez más, la riqueza natural y cultural del panorama andaluz, elementos de aprovechamiento social, posibles factores para la elaboración y diseño de rutas caracterizadas ante todo por la valoración y el cuidado paisajístico y cultural.

\section{RESULTADOS Y DISCUSIÓN}

\subsection{Sistema de Información Geográfica (SIG)}

Dicho SIG se ha centrado en la distribución y análisis territorial de los molinos de vientos del territorio andaluz y se compone de dos partes: la localización geográfica cuyas coordenadas han sido extraídas del trabajo de campo, y la información geográfica procedente de la fase RIG.

Para la función de consulta, gestión y análisis de la información geográfica, se ha empleado el software gvSIG con licencia GPL (del inglés, General Public License) en su versión de escritorio 1.11, procediendo de un proyecto realizado en España por la Generalitat Valenciana programado en lenguaje Java.

Aunque existen trabajos relacionados que constituyen una aproximación a uno de los objetivos del trabajo de investigación (Pérez Martín et al., 2011), el presente artículo muestra una nueva metodología para trasladar los resultados del SIG a Internet, potenciando su difusión.

Para establecer las rutas molinares se han considerado dos variables: la primera variable requiere que los molinos susceptibles de ser visitados reúnan una serie de características como la integridad del edificio y de su maquinaria, calidad paisajística del entorno donde se ubiquen o el acceso, entre otras. Sin embargo, es requisito indispensable alcanzar una calificación mínima de la valoración paisajística de 'Buena' para ser considerado como molino de la ruta propuesta.

La segunda variable es la distancia entre molinos de viento. El medio de transporte que más distancia permite recorrer es el vehículo, y por tanto, será más sencillo encontrar un mayor número de molinos, puesto que se trabaja en un área de influencia mayor. Para este escenario se ha considerado una ruta cuya distancia no sobrepase los $48 \mathrm{Km}$, con una zona de influencia de cada molino de viento de $8.000 \mathrm{~m}$ de radio, pensando que el número máximo de molinos visitables sean 6 , y aprovechando las carreteras de titularidad pública en buen estado para su desplazamiento, evitando las pistas de tierra.

Así por ejemplo y para el caso de Almería, se ha realizado un primer análisis gráfico aproximado para comprobar la viabilidad y planificar las posibles rutas molinares (Fig. 3), de manera que se muestran las diferentes zonas de influencia por colores para los molinos de viento almerienses. El área más interior (de color verde) corresponde a un radio de influencia de $1.750 \mathrm{~m}$ apta para desplazarse caminando, el área intermedia (de color cian) tiene por radio $2.000 \mathrm{~m}$ mostrando el recorrido en bicicleta o caballo, y el área más exterior (de color rojo) es de $8.000 \mathrm{~m}$ propia para el desplazamiento con vehículos. 
Figura 3

ANÁLISIS POR ÁREAS DE INFLUENCIA DE LOS MOLINOS DE VIENTO DE ALMERÍA

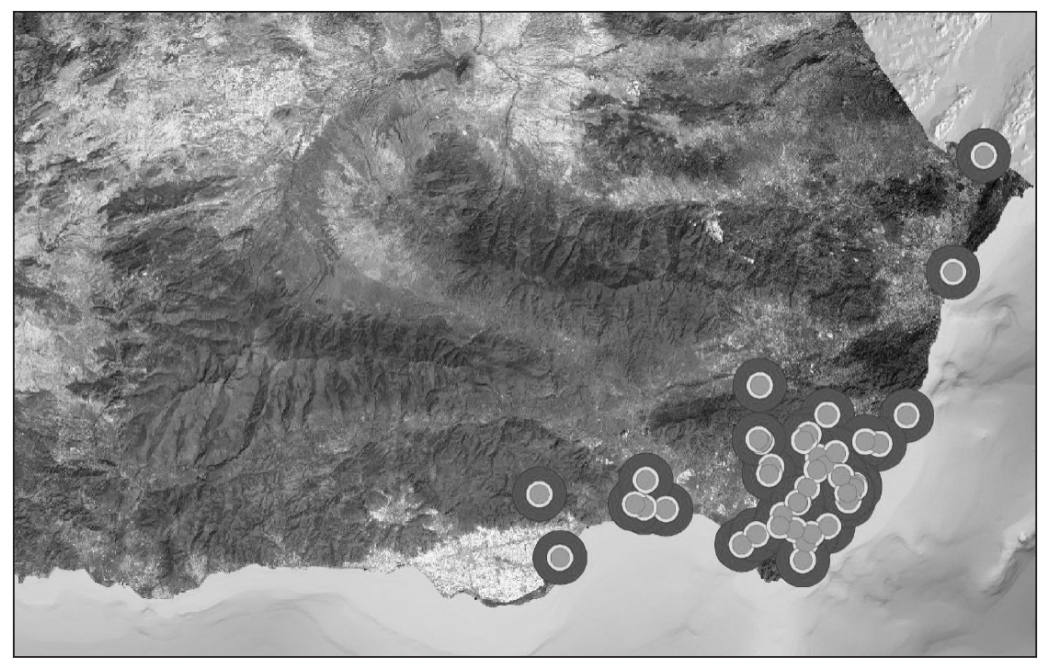

Fuente: Elaboración propia.

Como ejemplo, se expone a continuación la ruta molinar a vehículo diseñada en la provincia de Almería, que cumple con las restricciones impuestas por las dos variables tenidas en cuenta, y generada por el SIG temático (Fig. 4) contando como cartografía base la obtenida mediante servidores Web Map Service (WMS) del geoportal de Infraestructura de Datos Espaciales de Andalucía (IDE Andalucía).

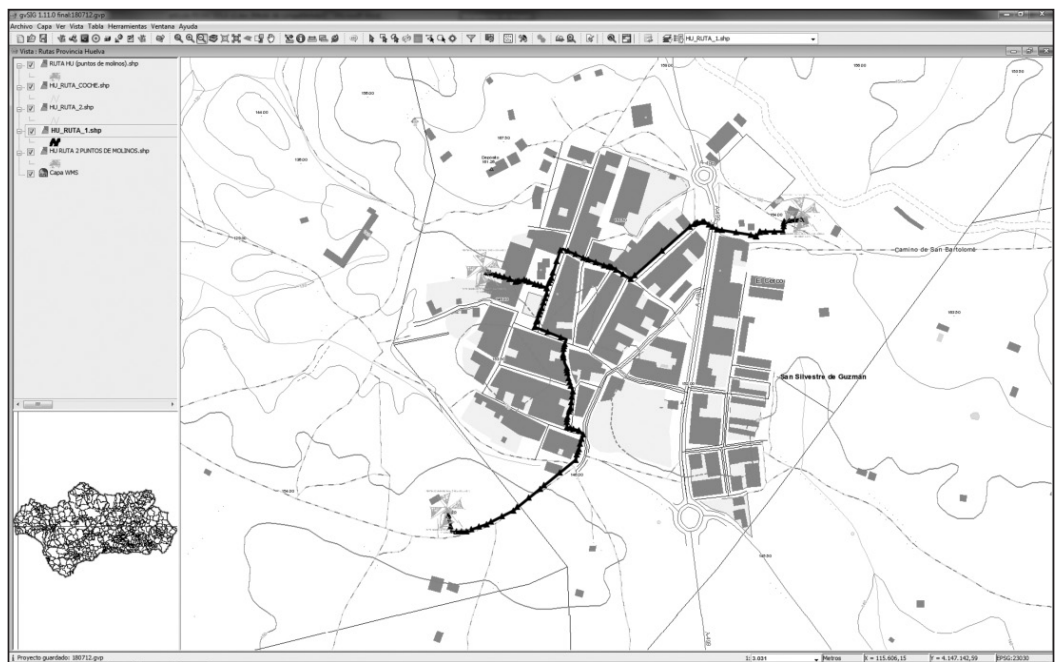

Fuente: Elaboración propia. 
A partir de esta información, se ha realizado la difusión de las rutas molinares en Internet. Para ello, una de las herramientas más populares para la difusión de material multimedia a través de Internet es el entorno que genera aplicaciones de tipo Flash, siendo una plataforma que es admitida por la mayoría de los sistemas operativos de teléfonos de última generación (Smartphone) y PDA (del inglés, Personal Digital Assistant), consiguiéndose una experiencia satisfactoria por parte del usuario.

La aplicación Flash se ha realizado gracias al software de Adobe Flash CS4, anteriormente conocido como Macromedia Flash, y desarrollado por Adobe Systems Incorporated, herramienta que trabaja con fotogramas o cuadros donde se integran datos vectoriales, imágenes ráster, sonido, código de programación orientado a objetos como es el caso de ActionScript 3.0 o vídeo, entre otros. En concreto, la información que se puede encontrar en la herramienta Flash es el inventario de los molinos de viento de Andalucía así como las rutas molinares propuestas (Fig. 5).

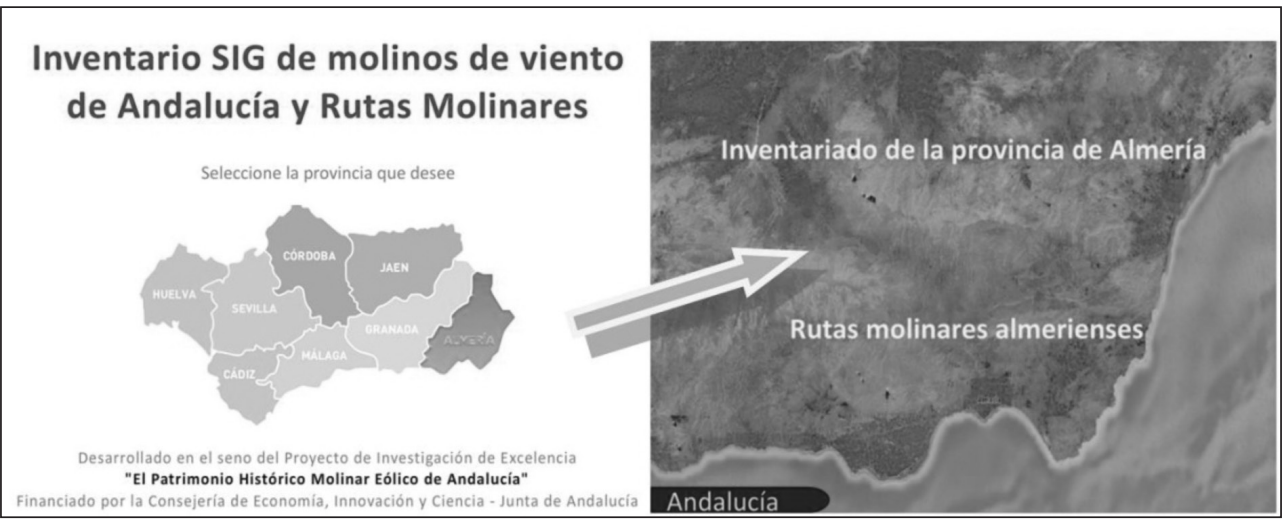

Fuente: elaboración propia.

El inventariado de molinos ofrece la distribución de los molinos de viento que muestra el visor (Fig. 6), cuya cartografía base procede de Google Maps. De esta manera, se puede explorar en tiempo real el territorio en el cual están ubicados los molinos de viento. Además, pinchando sobre cada molino aparece una ventana emergente donde existe una breve descripción que explica los aspectos más relevantes del mismo (Fig. 7), complementado con las coordenadas en el sistema del geoide WGS 84.

En lo que concierne a las rutas molinares, la información que se ofrece es la posibilidad de navegar a través de una ortofotografía (Fig. 8), donde aparece el trazado de la ruta molinar, completándose con una galería fotográfica donde se recogen las fotografías más representativas de cada molino de viento que pertenece a la ruta molinar consultada. 
Figura 6

INVENTARIO DE MOLINOS DE ALMERÍA CON LA CARTOGRAFÍA DE GOOGLE MAPS

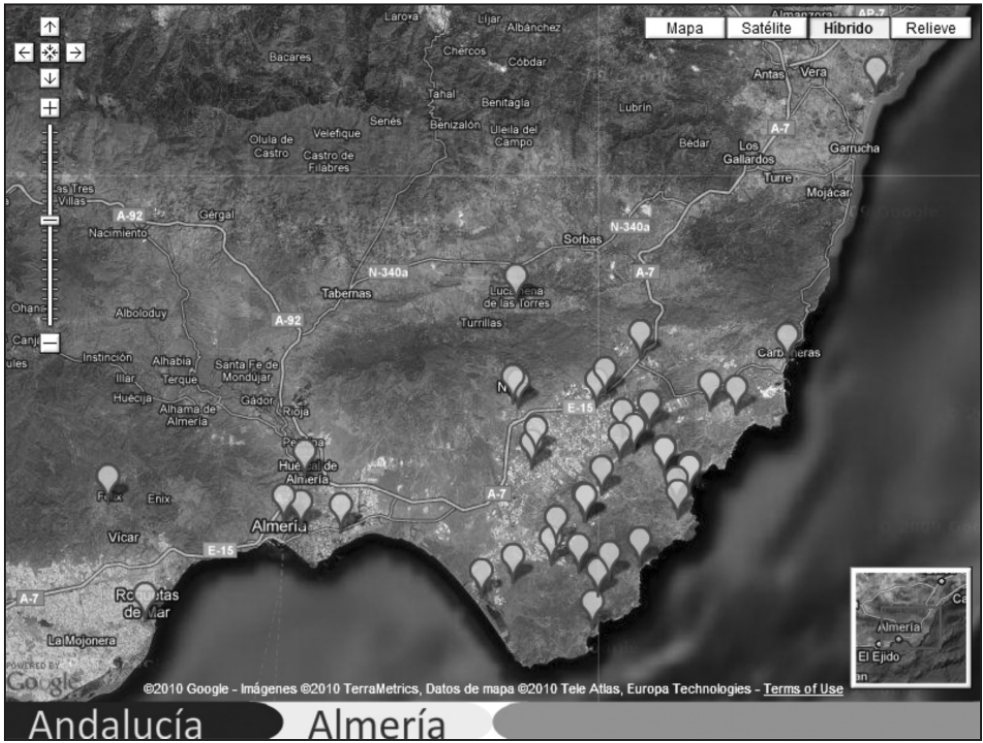

Fuente: Elaboración propia.

Figura 7

DESCRIPCIÓN GENERAL DE UN MOLINO

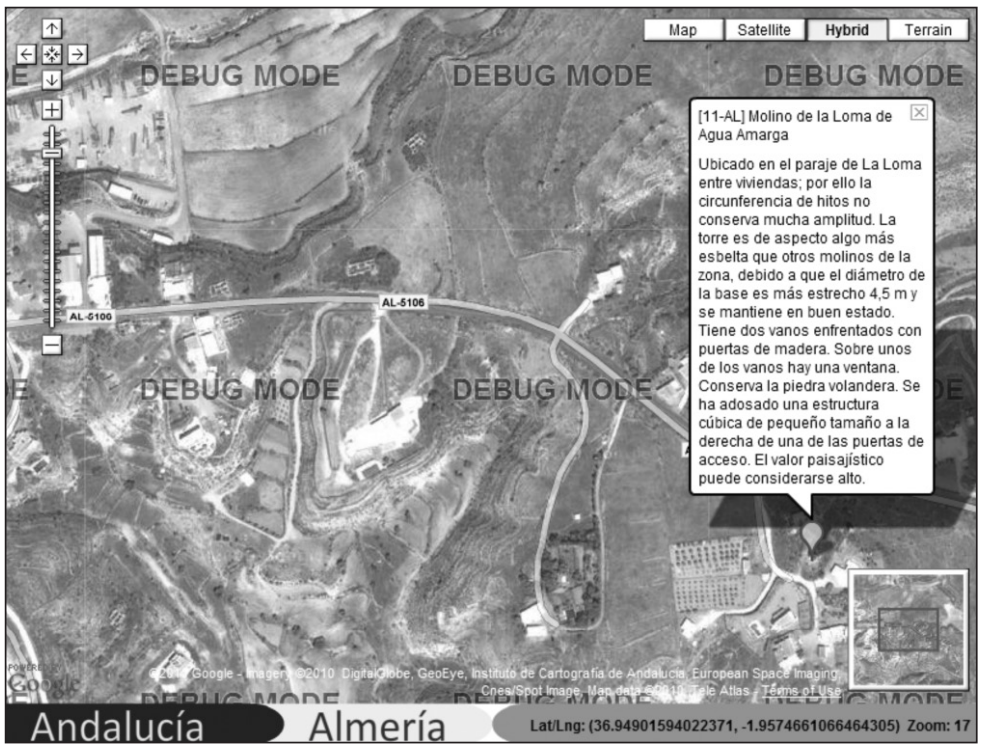

Fuente: Elaboración propia. 


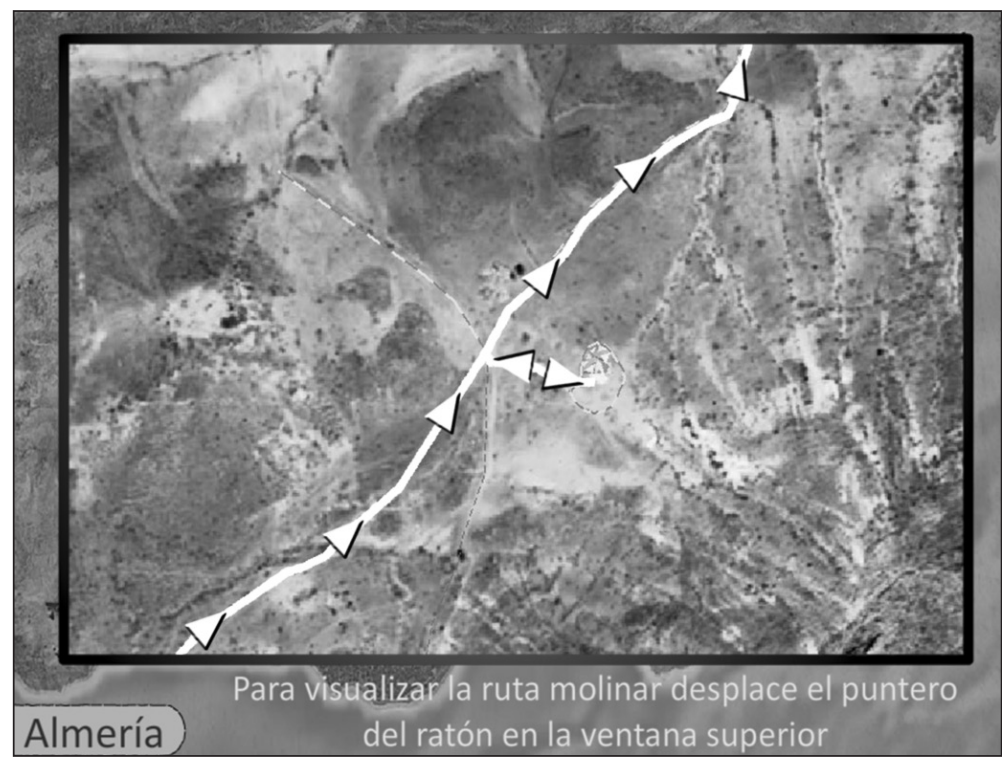

Fuente: Elaboración propia.

\subsection{Propuesta de rutas molinares}

\subsubsection{Ruta molinar por la provincia de Almería}

En la provincia de Almería, se propone una única ruta ‘a vehículo’ en pleno Parque Natural Cabo de Gata-Níjar, que ofrece un pintoresco itinerario a base de llanos, pequeñas cadenas montañosas y riqueza geomorfológica (López Galán, 2010), un territorio desolado, árido, desértico y escasamente antropizado (Fernández Cacho et al., 2010). Las localidades que se integran en este itinerario son Fernán Pérez, Las Negras, Los Escullos, Pozo de los Frailes y San José. Además, muchos de estos molinos de dicho Parque Natural han sido inscritos en el Catálogo General del Patrimonio Histórico Andaluz (López Galán et al., 1999).

En Fernán Pérez se alza el molino de Manuel Gil desde donde se observa un paisaje con una calidad paisajística de 'Mediocre' tras la valoración in situ (Fig. 9), con un total de 39,50 puntos, y en las Negras se ubica el Molino de Abajo, siendo la valoración obtenida desde este punto de observación de 'Notable' con un total de 58,25 puntos.

Por otro lado, el molino de Abajo de las Negras presenta una valoración de 'Notable' con 58,25 puntos.

Asimismo, el Molino de los Roperos se ubica cerca de la localidad de Los Escullos, y desde allí la valoración paisajística obtenida es de 'Muy Buena' con un total de 74,50 puntos.

Por último, el molino situado en la localidad de Pozo de los Frailes ofrece una valoración paisajística de 'Buena' con un total de 51,25 puntos, y asimismo en el municipio de San José, 
se emplaza el Molino de El Collado de los Genoveses que obtiene una calidad de 'Buena' con un total de 48,50 puntos.

Figura 9

PANORÁMICA DESDE EL MOLINO DE VIENTO DE FERNÁN PÉREZ (ALMERÍA)

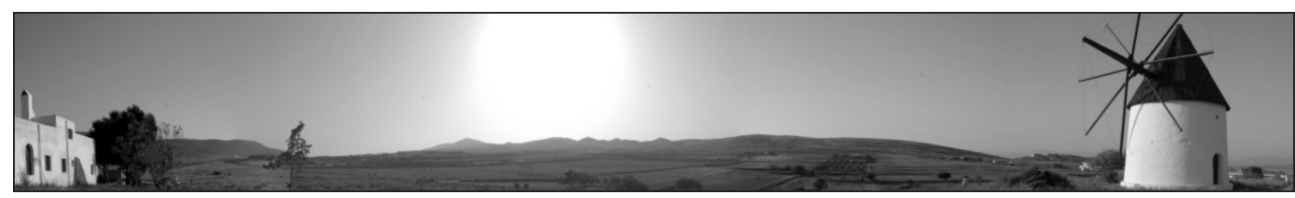

Fuente: Elaboración propia.

\subsubsection{Rutas molinares por la provincia de Huelva}

En la provincia de Huelva se presentan varias localidades con molinos de viento que están enmarcados en bellos entornos de la comarca del Andévalo Occidental donde priman el monte bajo y amplias llanuras, área predominantemente agropecuaria con baja densidad de población y, en la actualidad, en crisis en los sectores económicos tradicionales.

Los municipios que integran la ruta molinar propuesta para la provincia de Huelva son: El Almendro, Villanueva de los Castillejos, San Silvestre de Guzmán, El Granado y Sanlúcar de Guadiana. Para esta comarca se han propuesto dos rutas molinares 'a pie' y una ruta 'a vehículo'. Las rutas 'a pie' comprenden, por un lado, la visita de los distintos molinos de viento de las localidades de El Almendro y Villanueva de los Castillejos, y por otro, los ingenios que se alzan en la localidad de San Silvestre del Guzmán.

En la primera ruta molinar 'a pie' se visitan los dos molinos que se alzan sobre el Cabezo Pie Castillo en El Almendro (el molino de José Gómez García y el molino de Cabezo Pie Castillo) y el Molino de Zahurdón en Villanueva de los Castillejos. Tomando los molinos de viento como puntos de observación para evaluar la calidad paisajística se obtienen diversos resultados: desde Cabezo Pie Castillo la valoración paisajística es de 'Muy Buena', con un total de 73,37 puntos, mientras en el Molino de Zahurdón, la calidad obtenida es de 'Buena', con un total de 54,75 puntos.

La segunda ruta molinar 'a pie' recorre el pequeño municipio de San Silvestre de Guzmán donde se erigen tres ingenios: Molino de Vilán, Molino de Tía Juana Correa y Molino de Juan Francisco Cantero. Los resultados obtenidos en cuanto a la valoración paisajística desde los tres puntos de observación presentados son de 'Muy Buena' para el Molino de Vilán, con un total de 73,75 puntos. Desde el Molino de Tía Juana Correa la calidad es de 'Notable', con un total 66,25 puntos, y por último, desde el Molino de Juan Francisco Cantero la calidad paisajística obtenida es de 'Notable' con un total de 65,50 puntos.

La ruta propuesta 'a vehículo' recorre las localidades de El Granado y Sanlúcar de Guadiana. En El Granado se alzan dos ingenios: el de La Solana y el de El Santo. La calidad paisajística obtenida desde el Molino de La Solana es de 'Muy Buena' con un total de 74 puntos, coincidiendo también con el Molino de El Santo, con un total de 75 puntos. En Sanlúcar de Guadiana sobre un elevado cerro (Fig. 10), junto al río Guadiana, frontera ya con Portugal, se erigen dos ejemplares molinares que ofrecen resultados de valoración paisajística 'Muy Buena' con un total de 79 puntos. 


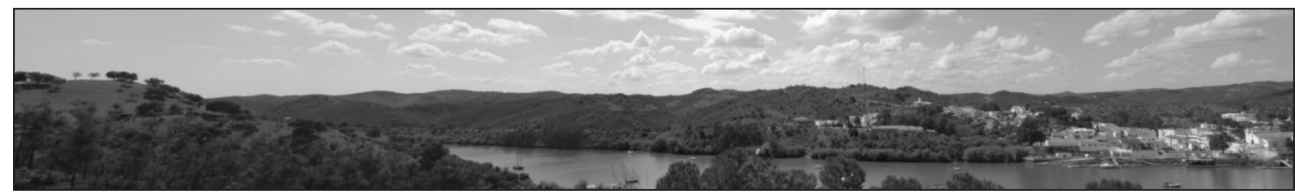

Fuente: Elaboración propia.

El ejemplar de El Granado (Molino de La Solana), junto a los molinos de viento de las localidades de El Almendro y Puebla de Guzmán, han sido incluidos en una ruta cultural creada por el Centro de Documentación del Instituto Andaluz de Patrimonio Histórico, que recibe el nombre de Ingenios del aire, molinos de viento en la comarca del Andévalo (Huelva) (Zafra Costán, 2009), con la finalidad de acercar a los diferentes usuarios la diversidad patrimonial de Andalucía (Carrera Díaz, 2006).

\subsubsection{Ruta molinar por la provincia de Cádiz}

En la localidad gaditana de Vejer de la Frontera, perteneciente al litoral de Cádiz-Estrecho, se propone una única ruta molinar 'a pie' que recorre los seis ejemplares que se alzan en dicho municipio: Molino de Santa Inés, Molino de Márquez, Molino de Buenavista o del Morillo, Molino de San José, Molino de San Francisco y Molino de San Antonio (estos tres últimos emplazados en la barriada de San Miguel, finca de las Tres Avemarías). Todos ellos están orientados hacia el Parque Natural de la Breña y Marismas de Barbate, zona poblada con diversas variedades arbóreas como pinos piñoneros, carrascos y acebuches.

Los resultados obtenidos en estos puntos de observación han sido de 'Muy Buena' para el Molino de Santa Inés (Fig. 11) con un total de 76,50 puntos, de 'Excelente’ para el Molino de Márquez, y de 'Excelente' también con un total de 92,50 puntos para el Molino de Buenavista; por otro lado, para los emplazados en la finca de las tres Avemarías la calidad paisajística es de 'muy buena' con un total de 68 puntos.

Figura 11

PANORÁMICA DESDE LOS MOLINOS DE VIENTO DE VEJER DE LA FRONTERA (CÁDIZ)

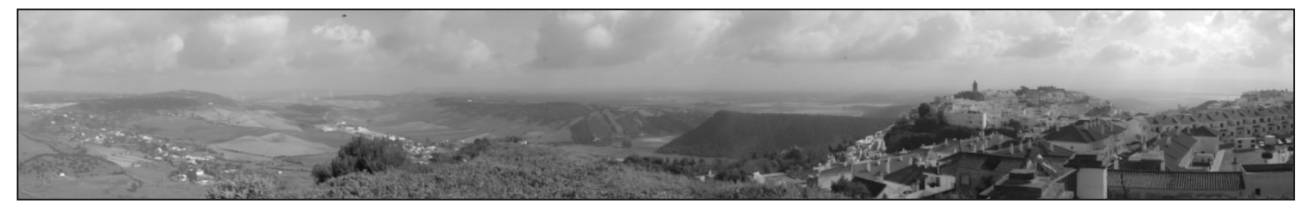

Fuente: Elaboración propia.

\subsection{Las rutas molinares: Desarrollo rural y sostenibilidad}

La gran mayoría de estos ejemplares se encuentran localizados en pequeños municipios del ámbito rural (Pardo Abad, 2010) que carecen de una actividad socioeconómica sostenible debido al abandono y decadencia de actividades agropecuarias tradicionales cuya producción 
de materias primas sobre todo alimenticias, eran la base económica primordial de estas localidades (Bustos Gisbert, 2006).

Hace décadas, la vida en estas áreas rurales giraba en torno al campo siendo las tierras aprovechadas al máximo, pero con la llegada de nuevas e innovadoras maquinarias e industrias, estos municipios sufrieron un fuerte retroceso, sus campos se despoblaron y abandonaron, y sus habitantes se marcharon a grandes centros urbanos en busca de nuevas oportunidades; aun así, son claros ejemplos de un nítido equilibrio entre naturaleza y actividades agrarias donde se testimonia el valor fundamental de la historia e identidad de esas tierras.

Las distintas áreas rurales que este estudio recoge, han sido territorios creados a lo largo de un lento proceso histórico, en el que se ha ido confeccionando una riqueza paisajística y patrimonial, una marcada identidad que se refleja tanto en sus costumbres y tradiciones como en su arquitectura, una arquitectura tradicional que como bien indica el profesor Juan Agudo «...forma parte de un contexto amplio que nos refleja la estructura social, los valores, las aspiraciones, las costumbres, etc...de un pueblo» (Agudo Torrico, 2001).

En la actualidad se está viviendo un proceso de revalorización de los ámbitos rurales convirtiéndose en destinos turísticos que hacen evadir al visitante de la monotonía y del estrés que provocan las grandes urbes. Esta nueva percepción hacia 'lo rural' ha conllevado un mayor desarrollo, inversión y protección del mundo rural, recuperando la importancia territorial perdida en las últimas décadas, sin obviar el elemento fundamental en este proceso, que no es sino la sostenibilidad entendida como una nueva dimensión necesaria del propio desarrollo rural (González Regidor, 2008).

En las áreas rurales se concentran la mayoría de los recursos naturales, históricos y culturales, ambientales y paisajísticos, etnológicos y antropológicos, siendo necesarias iniciativas de fomento de desarrollo sostenible que conviertan a estas zonas en lugares con buenas dinámicas territoriales y socioeconómicas (Maya Frades e Hidalgo González, 2009). Para ello la Ley 45/2007, de desarrollo sostenible del medio rural acoge los siguientes objetivos:

- Mantener y ampliar la base económica del medio rural mediante la preservación de actividades competitivas y multifuncionales, y la diversificación de su economía con la incorporación de nuevas actividades compatibles con un desarrollo sostenible.

- Mantener y mejorar el nivel de población del medio rural y elevar el grado de bienestar de sus ciudadanos, asegurando unos servicios públicos básicos adecuados y suficientes que garanticen la igualdad de oportunidades y la no discriminación, especialmente de las personas más vulnerables o en riesgo de exclusión.

- Conservar y recuperar el patrimonio y los recursos naturales y culturales del medio rural a través de actuaciones públicas y privadas que permiten su utilización compatible con un desarrollo sostenible.

La sostenibilidad es un concepto que fue definido en el Informe Bruntland de la Comisión Mundial sobre Medio Ambiente y Desarrollo en 1987 (AA.VV., 1987) para paliar entre otros problemas, la vulnerabilidad y la pobreza medioambiental. En él se dice que la sostenibilidad es «el desarrollo que satisface necesidades presentes sin perjudicar la capacidad de las generaciones futuras para satisfacer sus propias necesidades...». 
Así pues, la sostenibilidad es la herramienta básica en cualquier ámbito social necesaria para lograr un cambio sustancial tanto a nivel económico, turístico, como medioambiental.

En el artículo 29 de la anteriormente citada Ley 45/2007, una de las medidas propuestas para dicho desarrollo a nivel cultural es la creación de redes de espacios culturales reutilizando el patrimonio existente y garantizando su sostenimiento y accesibilidad, además de la protección y restauración del patrimonio histórico artístico de los municipios rurales.

El patrimonio no se ha de banalizar, se ha de percibir como generador de riqueza y motor de desarrollo territorial como vía turística que promocione las distintas áreas obteniendo rentabilidad para los municipios y la comarca, apoyada y orientada hacia el turismo sostenible que como se definió en el Foro Europeo del Turismo «es aquel que es viable desde el punto de vista económico y social sin perjudicar el medio ambiente ni la cultura local»(AA.VV., 2002).

En la década de los noventa, la UNESCO afirmó que el patrimonio natural y cultural es el recurso primordial para un desarrollo territorial sostenible, es por ello que se crean distintos programas europeos para intervenir en las áreas menos autosuficientes, programas como LEADER Y PRODER, que de alguna manera han ayudado al desarrollo local de los diversos espacios rurales fomentando el embellecimiento de los mismos y un mayor desarrollo turístico que a su vez promoverán nuevas oportunidades respetando la integridad cultural, ecológica y biológica.

Antaño, la energía eólica era aprovechada con fines mecánicos; hoy día la energía cinética que produce el viento es transformada en energía eléctrica a través de aerogeneradores que ocupan amplias zonas con potencial eólico, lugares privilegiados con mayor exposición visual como crestas de montañas o zonas costeras, donde hace décadas se construían molinos de viento para la molienda del cereal, y que hoy día proliferan de forma descontrolada causando un gran impacto paisajístico negativo. De hecho, en la metodología de valorización del paisaje empleada se han considerado como elementos que rompen la línea del horizonte, restando valor paisajístico final. Por ello, es muy necesaria la introducción de los parques eólicos en documentos de planeamiento territorial que, superando los intereses no siempre claros de los municipios, manifiesten qué zonas y con cuántos molinos pueden establecerse en los distintos territorios.

Por ejemplo, la provincia de Almería ofrece un gran potencial eólico, y son muchos los municipios que están habitados por estos nuevos ingenios, aunque a diferencia de los de antaño, se encuentran con la imposibilidad de ser instalados en el Parque Natural Cabo de Gata-Níjar debido a la protección ambiental que recae sobre él. Por su parte, la Comarca del Andévalo Occidental en Huelva, posee 151 aerogeneradores que pueblan sus tierras, siendo el complejo eólico con más potencia instalada después del existente en Escocia (Marín Cejudo, 2011). Asimismo, la provincia de Cádiz cuenta con 63 parques eólicos instalados (AA.VV., 2011), convirtiéndose en la provincia andaluza con más aerogeneradores y la pionera en desarrollar este tipo de energía renovable a nivel nacional.

Como se puede comprobar, son zonas rurales involucradas en la búsqueda del desarrollo, de una mejora a nivel socioeconómico no sólo basado en el fomento de lo patrimonial, sino apostando por los recursos sostenibles beneficiosos para el territorio y sin perder la memoria social, objetivo del desarrollo rural de las distintas comarcas. 


\subsubsection{Provincia de Almería}

Entre los espacios rurales donde aún se alzan molinos de viento en la provincia de Almería, pertenecientes todos ellos a la Comarca de Níjar, se encuentra Fernán Pérez donde se erige el molino de Manuel Gil; Las Negras, que presenta el molino de Abajo y el molino de Arriba del que tan sólo queda la torre; Los Escullos, con el molino de los Roperos acondicionado hoy día como vivienda; el Pozo de los Frailes, con molino de igual nombre; San José, con el molino del Collado de los Genoveses (Fig. 12), en perfecto estado de conservación puesto que fue intervenido al igual que los anteriormente mencionados, -exceptuando el molino de Arriba de Las Negras y el de los Roperos en Los Escullos-, gracias a un programa de actuaciones llevados a cabo por las Consejerías de Medio Ambiente y Cultura de la Junta de Andalucía, para la restauración y consolidación de los molinos de viento de Cabo de GataNíjar en el bienio 2007-2008.

En la provincia de Almería, todos estos ingenios se enclavan en pequeños municipios de áreas rurales que no llegan a sumar en total más de 2.500 habitantes. Durante largo tiempo los pobladores de estas zonas trabajaron sus tierras ya que el $80 \%$ del espacio fue dedicado a cultivos extensivos del cereal, y otros muchos emigraron y abandonaron el territorio debido a la escasez de oportunidades socioeconómicas. Hoy en día, la mayor parte de la población que habita la zona, vive de la actividad turística o de la nueva agricultura bajo plástico (AA. VV., 2005a), ya que estos municipios pertenecen al Parque Natural Cabo de Gata-Níjar, zona especialmente protegida por sus valores ecológicos, ambientales, paisajísticos y culturales (Mendoza y Navarro, 2006).

\section{Figura 12}

MOLINO DE VIENTO DEL COLLADO DE LOS GENOVESES (ALMERÍA)

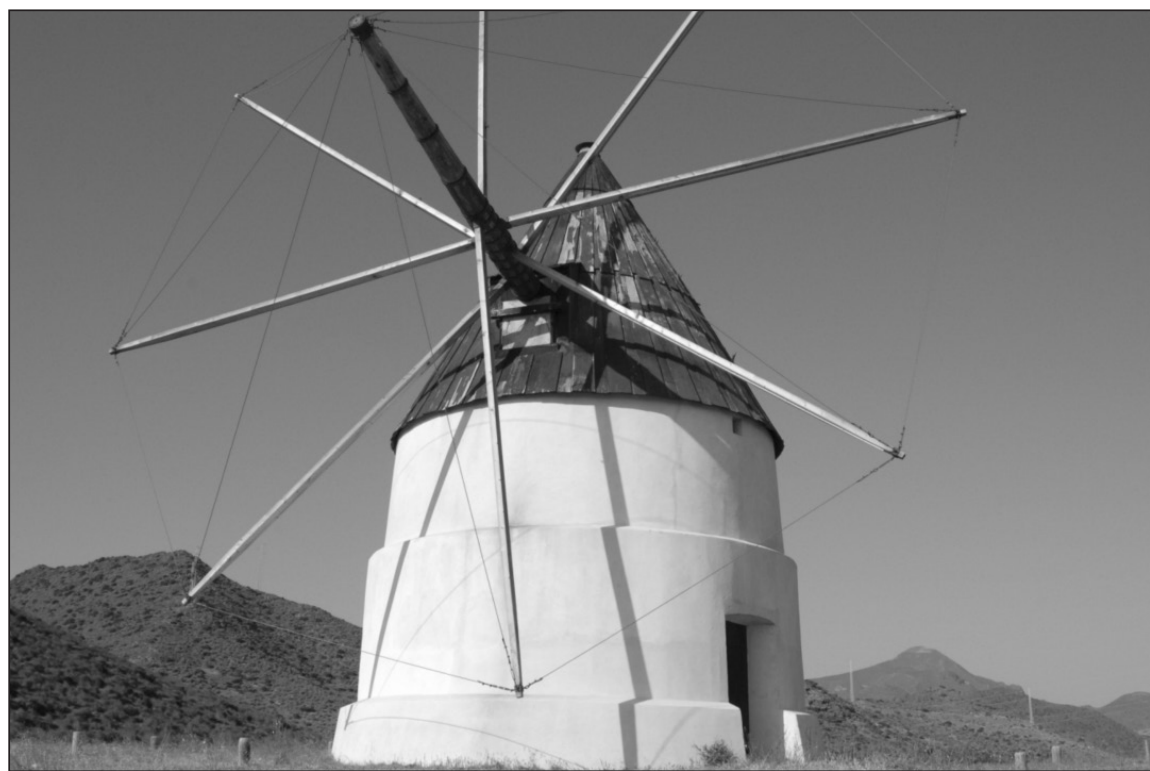

Fuente: Elaboración propia. 


\subsubsection{Provincia de Huelva}

En la provincia de Huelva, el patrimonio histórico molinar eólico es referente en toda la comarca del Andévalo occidental. En el municipio de El Almendro se hallan dos molinos sobre el Cerro Pie de Castillo; en la localidad vecina de Villanueva de los Castillejos se alza el molino de Zahurdón; en San Silvestre de Guzmán, los molinos de Vilán, Tía Juana Correa y Juan Francisco Cantero; en El Granado, el molino de La Solana parece proteger la pequeña localidad junto al molino de El Santo, al otro extremo del mismo, y Sanlúcar de Guadiana, posee otros dos ejemplares sobre un cerro desde donde se divisan unas bellas panorámicas del río Guadiana y de Portugal.

Todos estos municipios sobrevivieron décadas atrás gracias a la explotación agropecuaria, forestal y a la práctica cinegética. Posteriormente, se optó por paliar la escasez de recursos gracias a nuevos horizontes agrarios y a nuevas expectativas económicas relacionadas con el turismo rural.

\subsubsection{Provincia de Cádiz}

En la provincia de Cádiz, y concretamente en la localidad de Vejer de la Frontera (Comarca de La Janda), se erigen seis ingenios de los cuales cuatro son propiedad municipal, y otros dos de propiedad privada. En la barriada de San Miguel, se ubican los molinos de San José, San Francisco y San Antonio, todos ellos en buen estado de conservación e intervenidos por la Consejería de Cultura en el año 2000. En el Cerro de los molinos se presentan el molino de Santa Inés, molino de Márquez y molino del Morillo, los cuales muestran unas espectaculares vistas de la Comarca y del Parque Natural de la Breña y Marismas de Barbate.

Asimismo, como actividades complementarias a las rutas molinares, en la localidad de Vejer de la Frontera se crea la Asociación cultural 'Al uso del Burro', que fomenta la revalorización arquitectónica, paisajística y la recuperación de la memoria del municipio a través de rutas en burro. Además de ello, en el mismo emplazamiento donde se ubican los molinos en la finca de las Tres Ave Marías, se construyó hace unos años un Centro de Interpretación del Viento, aunque hoy día permanece cerrado.

\section{CONCLUSIONES}

Andalucía es una de las regiones con mayor riqueza de valores y recursos patrimoniales, tanto culturales, ambientales como paisajísticos, fruto de su medio natural y de su historia humana, por ello, desde la concienciación social se trabaja por integrar a los molinos de viento como bien emblemático donde la ciudadanía participe y se involucre en su recuperación y puesta en valor, ya no sólo a nivel arquitectónico sino también geográfico, histórico, paisajístico, etnográfico y antropológico, aumentando la comprensión de lo humano.

Hoy día, dichos ingenios que han sobrevivido al paso de las décadas, forman parte de un amplio repertorio de arquitectura vernácula que ofrecen o pueden ofrecer, nuevas expectativas y recursos culturales y/o turísticos a las comarcas donde se enclavan. 
Gracias a la investigación llevada a cabo y presentada en este artículo, se ha desarrollado una metodología para la creación de rutas molinares y su difusión a través de Internet cuyas principales variables han sido, el estado de conservación y acceso a los mismos que incluye la valorización del paisaje, así como la distancia entre ellos, lo que determina el tipo de ruta 'a pie' o 'a vehículo'. Por tanto, se cubre un doble objetivo: en primer lugar, dar a conocer estas herramientas al lector especializado, y por otro, difundir este tipo de iniciativas a un público general para que redunde en un posible incremento del desarrollo rural desde la sostenibilidad.

Actualmente, existe un continuo interés por recuperar y conservar el medio rural, y por ello, la sociedad demanda una buena gestión ya no sólo hacia el patrimonio arquitectónico sino hacia el patrimonio paisajístico, medioambiental e inmaterial. De esta manera, las zonas rurales cobran mayor interés ante las distintas comunidades fomentando de alguna manera su desarrollo a través de nuevos programas e iniciativas que favorezcan a las distintas localidades conduciéndolas hacia posibles fuentes de empleo, turismo, y valoración de sus entornos.

En consecuencia, todos los municipios integrantes en las rutas molinares propuestas en esta investigación, son áreas rurales involucradas en políticas paisajísticas y medioambientales, como pilares de desarrollo sostenible que favorecen a los distintos territorios que apuestan por la energía renovable, y siendo el futuro de las generaciones venideras, aunando tradición y modernidad.

Son varios los programas que de alguna manera integran a la ciudadanía con el propio bien y su entorno aunque nunca suficientes para su plena valorización. La mayoría de los ejemplares aquí expuestos han sido objeto de intervenciones por parte de la Consejería de Cultura de la Junta de Andalucía pero no se les ha ofrecido una función a desarrollar que haga que la construcción permanezca activa y abierta a sus pobladores, ya que el principal destinatario de la gestión patrimonial es la persona que vive 'en' o ‘cerca de' este patrimonio, que es quien debe apreciar el bien patrimonial, y los que en última instancia han de protegerlo y conservarlo con el objetivo de mantener viva la historia de su municipio.

Así pues, esta investigación ha contribuido a conocer estas construcciones un poco más, a promover la sensibilidad social hacia sus valores y a proponer unas rutas turísticas para su visita. Pero sobre todo, dado que lo importante es hablar de modelos de desarrollo, hay que tener en cuenta el papel tan activo que han tenido los grupos de desarrollo rural en Andalucía, precisamente muy centrados en este patrimonio vernáculo, muchas veces considerado menor desde las instancias centrales.

\section{AGRADECIMIENTOS}

La investigación expuesta en el presente artículo se ha realizado en el seno del Proyecto de Investigación de Excelencia titulado El patrimonio histórico molinar eólico de Andalucía (P07-HUM-2485), financiado por la Consejería de Economía, Innovación y Ciencia de la Junta de Andalucía, y gracias también al Programa de Formación Nacional del Profesorado Universitario (FPU) del Ministerio de Educación, Cultura y Deporte de España. 


\section{BIBLIOGRAFÍA}

AA.VV. (1987): Nuestro futuro común (Informe Bruntland). Comisión Mundial sobre Medio Ambiente y Desarrollo.

AA.VV. (2000): Convenio Europeo del Paisaje. Bruselas. Consejo de Europa, 1-8.

AA.VV. (2002): Foro Europeo del Turismo. Bruselas.

AA.VV. (2005a): El viento y el agua en la construcción de un paisaje cultural. Sevilla. Junta de Andalucía, Consejería de Cultura.

AA.VV. (2005b): «Diversidad y naturalidad paisajística de las comarcas de Andalucía». Segundo Informe de desarrollo territorial de Andalucía. 89-100.

AA.VV. (2008): Convención de Patrimonio Mundial.

AA.VV. (2011): Eólica'11 (Anuario). Asociación empresarial eólica.

AGUDO TORRICO, J. (1999): «Arquitectura tradicional y patrimonio andaluz». Demófilo: Revista de cultura tradicional, $\mathrm{n}^{\mathrm{o}} 31,13-32$.

AGUDO TORRICO, J. (2001): Arquitectura tradicional. Proyecto Andalucía. Antropología. Arquitectura vernácula. Sevilla.

ALEGRE CARVAJAL, E. (2003): «La popularización de la arquitectura». UNED. Espacio, Tiempo y Forma, serie VII, Historia del Arte, t. 16, 81-110.

BUSTOS GISBERT, M.L. (2006): «Crisis, recuperación y cambios en las áreas rurales regresivas». Ería, n $70,149-160$.

CAÑAS GUERRERO, I. (1995): Valoración del paisaje. Lugo. Universidad de Santiago de Compostela.

CARAVACA BARROSO, I.; COLORADO CAMPOS, D.; FERNÁNDEZ SALINAS, V.; PANEQUE SALGADO, P.; PUENTE ASUERO, R. y ROMERO MORAGAS, C. (1997): «El patrimonio cultural como factor de desarrollo en Andalucía». PH: Boletín del Instituto Andaluz de Patrimonio Histórico, n 20, 87-97.

CARO BAROJA, J. (1996): Tecnología popular española. Barcelona. Galaxia Gutenberg.

CARRERA DÍAZ, G. (2004): «La arquitectura vernácula de la Andalucía rural. Un análisis comparado de dos inventarios». ARA. Tierra sur. Patrimonio cultural y desarrollo rural en Andalucía, $\mathrm{n}^{\circ}$ 15, 24-29.

CARRERA DÍAZ, G. (2006): «Itinerarios y rutas: herramientas para la documentación y puesta en valor del patrimonio cultural». PH: Boletín del Instituto Andaluz de Patrimonio Histórico, $\mathrm{n}^{\circ} 60,52-59$.

FERNÁNDEZ CACHO, S.; FERNÁNDEZ SALINAS, V.; HERNÁNDEZ LEÓN, E.; LÓPEZ MARTÍN, E.; QUINTERO MORÓN, V.; RODRIGO CÁMARA, J.M. y ZARZA BALLUGERA, D. (2008): «Caracterización patrimonial del mapa de paisajes de Andalucía». PH: Boletín del Instituto Andaluz de Patrimonio Histórico, $\mathrm{n}^{\circ}$ 66, 16-31.

FERNÁNDEZ CACHO, S.; FERNÁNDEZ SALINAS, V.; HERNÁNDEZ LEÓN, E.; LÓPEZ MARTÍN, E.; QUINTERO MORÓN, V.; RODRIGO CÁMARA, J.M. y ZARZA BALLUGERA, D. (2010): Paisajes y patrimonio cultural en Andalucía: tiempo, usos e imágenes. Sevilla. Junta de Andalucía, Consejería de Cultura.

GOBSTER, P.H. y CHENOWETH, R.E. (1989): «The dimensions of aesthetic preferences: a quantitative analysis». Journal of Environmental Management, $\mathrm{n}^{\circ}$ 29, 47-72. 
GONZÁLEZ REGIDOR, J. (2008): «Medio rural y medio ambiente: por un desarrollo rural sostenible». Ambienta: la revista del Ministerio de Medio Ambiente, $\mathrm{n}^{\circ}$ 73, 28-33.

GUERRA DE HOYOS, C. (1997): «Patrimonio Cultural y Reutilización». PH: Boletín del Instituto Andaluz de Patrimonio Histórico, $\mathrm{n}^{\circ}$ 18, 93-96.

HERNÁNDEZ HERNÁNDEZ, M. (2009): «El paisaje como seña de identidad territorial: valorización social y factor de desarrollo, ¿utopía o realidad? ». Boletín de la Asociación de Geógrafos Españoles, $\mathrm{n}^{\circ}$ 49, 169-183.

HERNÁNDEZ LEÓN, E. (1997): «Antropología y Patrimonio Etnológico. PH: Boletín del Instituto Andaluz de Patrimonio Histórico, $\mathrm{n}^{\circ}$ 18, 83-85.

KRÜGER, F. (1950): «Geographie des traditions populaires en France». Cuadernos de estudios franceses. 255.

LEY 14/2007, de 26 de noviembre, del Patrimonio Histórico de Andalucía. Boletín Oficial de la Junta de Andalucía, de 19 de diciembre de 2007, n² 248, p. 6.

LEY 45/2007, de 13 de diciembre, Para el desarrollo sostenible del medio rural. Boletín Oficial del Estado, de 14 de diciembre de 2007, n $299,51339-51349$.

LÓPEZ GALÁN, J.S.; LÓPEZ GÓMEZ, J.F. y CIFUENTES VÉLEZ, E. (1999): Documentación para la inscripción genérica colectiva en el Catálogo General del Patrimonio Histórico Andaluz de los aljibes, norias, molinos, molinos de viento y molinos hidráulicos del Parque Natural de Cabo de Gata-Nijar (Almería). Almería. Junta de Andalucía, Delegación de la Consejería de Cultura.

LÓPEZ GALÁN, J.S. (2010): «Paisaje vivo, en permanente evolución». PH: Boletín del Instituto Andaluz de Patrimonio Histórico, $\mathrm{n}^{\circ} 73,42-87$.

LÓPEZ GÓMEZ, J.F. y CIFUENTES VÉLEZ, E. (2001): «Molinos, aljibes y norias: la cultura del paisaje en el Cabo de Gata». PH: Boletín del Instituto Andaluz de Patrimonio Histórico, no $37,192-198$.

MARÍN CEJUDO, A. (2011): El viento impulsa para Iberdrola el mayor parque eólico de la Europa continental. El Mundo. 10/03/11.

MARTÍNEZ YÁNEZ, C. (2010): «El patrimonio de la agricultura». ICOMOS. 1-10

MATA OLMO, R. (2008): «El paisaje, patrimonio y recurso para el desarrollo territorial sostenible. Conocimiento y acción pública». Arbor. Ciencia, Pensamiento y Cultura, $\mathrm{n}^{\circ}$ 729, 155-172.

MAYA FRADES, A. e HIDALGO GONZÁLEZ, C. (2009): «Nuevas funciones y desarrollos de los territorios rurales europeos: su necesaria adaptación a métodos de producción duraderos y sostenibles». Boletín de la Asociación de Geógrafos Españoles, n 49, 255 279.

MENDOZA, R.M. y NAVARRO, M. (2006): «Cabo de Gata. El agua y el viento». Medio Ambiente, $\mathrm{n}^{\circ}$ 54, 26-29.

PARDO ABAD, C.J. (2010): «El patrimonio industrial en España: análisis turístico y significado territorial de algunos proyectos de recuperación». Boletín de la Asociación de Geógrafos Españoles, n ${ }^{\circ}$ 53, 239-264.

PÉREZ MARTÍN, E.; HERRERO TEJEDOR, T.R., GÓMEZ-ELVIRA, M.A., ROJAS SOLA, J.I. y CONEJO MARTÍN, M.A. (2011): «Graphic study and geovisualization of the old windmills of La Mancha (Spain». Applied Geography, vol. 31, n 3, 941-949. 
RODRIGO CÁMARA, J.M.; DÍAZ IGLESIAS, J.M.; FERNÁNDEZ CACHO, S.; FERNÁNDEZ SALINAS, V.; HERNÁNDEZ LEÓN, E.; QUINTERO MORÓN, V.; GONZÁLEZ SANCHO, B. y LÓPEZ MARTÍN, E. (2012): «Registro de paisajes de interés cultural de Andalucía. Criterios y metodología». PH: Boletín del Instituto Andaluz de Patrimonio Histórico, $\mathrm{n}^{\circ} 81,64-75$.

ROJAS SOLA, J.I. y AMEZCUA OGÁYAR, J.M. (2005): «Southern Spanish windmills: technological aspects». Renewable Energy, vol. 30, nº 13, 1943-1953.

ROJAS SOLA, J.I.; GÓMEZ-ELVIRA GONZÁLEZ, M.A. y PÉREZ MARTÍN, E. (2006): «Computer-aided design and engineering: a study of windmills in La Mancha (Spain)». Renewable Energy, vol. 31, n 10, 1471-1482.

ROMERO TORRES, J. (2000): «Memoria y arquitectura popular». Gaceta de Antropología, $\mathrm{n}^{\mathrm{o}} 16,1-5$.

SILVA PÉREZ, R. (2009): «Agricultura, paisaje y patrimonio territorial. Los paisajes de la agricultura vistos como patrimonio». Boletín de la Asociación de Geógrafos Españoles, $n^{\circ} 49,309-334$.

SOBRINO SIMAL, J. (1997): «Balance de la situación del Patrimonio Industrial Andaluz». PH: Boletín del Instituto Andaluz de Patrimonio Histórico, $\mathrm{n}^{\circ}$ 21, 130-136.

TILLERÍA GONZÁLEZ, J. (2010): «La arquitectura sin arquitectos, algunas reflexiones sobre arquitectura vernácula». Revista: AUS (Valdivia), no 8, 12-15.

VIEDMA MUÑOZ, M. (1998): «Análisis de las direcciones de los vientos en Andalucía». Nimbus, $\mathrm{n}^{\mathrm{o}} 1,153-168$.

ZAFRA COSTÁN, P. (2009): «Ingenios del aire. Molino de viento en la comarca del Andévalo». PH: Boletín del Instituto Andaluz de Patrimonio Histórico, $\mathrm{n}^{\circ}$ 70, 40-71. 
